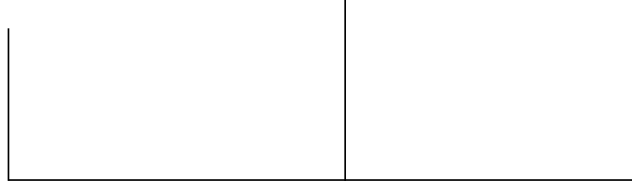

Rev. Latinoam. Psicopat. Fund., IV, 2, 178-179

Cultural Cognition and Psychopathology

(Cognição cultural e psicopatologia)

John F. Schumaker e Tony Ward (eds.)

Westport: Praeger, 2001

\title{
Cultural cognition and psychotherapy
}

\author{
Virginia Moreira
}

No que se refere à psicopatologia, assim como à psicologia clínica e à psicologia em geral, não é raro que se encontre, no meio acadêmico brasileiro, preconceitos em relação à importação e utilização de bibliografias. Não é à toa que, em bom português, ficamos com "um pé atrás”. São anos e anos de importação e repetição de modelos, na maioria das vezes, sem a necessária reflexão e revisão crítica imprescindíveis para sua aplicação na cultura brasileira, como já nos lembrava, constantemente, nosso grande Paulo Freire. No Brasil, ao contrário da maior parte dos países da América Latina, pode-se reconhecer, nas publicações mais atuais, uma lúcida crítica ao imperialismo do DSM-IV.

O livro de John Schumaker e Tony Ward (da Nova Zelândia e Austrália, respectivamente) é, sem dúvida, uma exceção, que pode ser útil ao leitor brasileiro, estudioso da psicopatologia. Trata-se de uma obra perpassada por um viés eminentemente crítico (presente na maioria dos seus capítulos, ainda que não em todos), não muito freqüente no meio das publicações em psicopatologia. Neste sentido, trata-se de uma importante contribuição no âmbito internacional das publicações nesta área.

John Schumaker apresenta o livro da seguinte maneira:

This book is an atempt to bring together the concepts of culture and cognition within the wider context of psychopathology. While it may seem obvious to some people that culture and cognition are important factors in the etiology of many forms of psychopathology, it is quite 
surprising how little has been done in terms of integrating these three areas into useful theoretical and treatment models. An analysis of the history of psychology explains in part why the field of psychology has been very slow to recognize and acknowledge the role of culture in normal as well as abnormal behavior.

O livro está dividido em três partes: a primeira aborda perspectivas históricas e teóricas, a partir do individualismo psicológico e de uma perspectiva antropológica da psicopatologia. A segunda parte versa sobre cognição cultural e desordens específicas tais como depressão, esquizofrenia, desordens alimentares, desordens de personalidade, entre outros. Na última parte se discutem implicações e aplicações tais como critérios culturais de justiça social e saúde mental.

Trata-se de uma interessante publicação, cuja importância não se restringe à abordagem teórica e clínica da psicopatologia a partir do enfoque cognitivo em psicologia, na medida em que os vários textos trabalham a cognição como forma de perceber, pensar e constituir o conhecimento sobre a psicopatologia em diferentes contextos culturais, o que incorre em profundas implicações para a constituição das várias patologias mentais. Além de uma revisão de literatura bastante atualizada sobre os estudos em psicopatologia e cultura, o texto mostra ao leitor como a cognição cultural dos distintos povos é um fator determinante na etiologia dos vários quadros psicopatológicos. Muito mais do que um simples passeio no âmbito dos resultados epidemiológicos de pesquisas transculturais realizadas sobre a psicopatologia nas últimas décadas - importantes, mas não suficientes - boa parte dos artigos que compõem o livro organizado por Schumaker e Ward coloca em questão a teoria e a clínica dos distúrbios psicopatológicos à luz de diferentes culturas e das sociedades ocidentais da chamada pós-modernidade. 